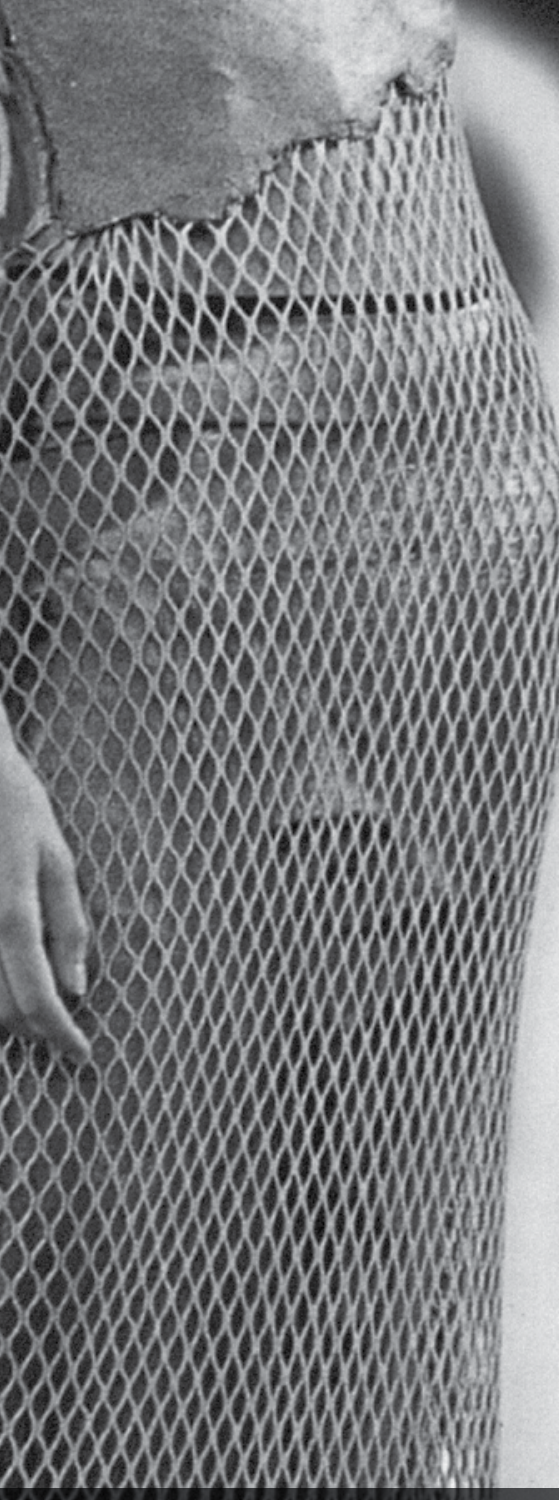

Fonte: KODA, Harold. Extreme Beauty: the body transformed. Nova York: The Metropolitan Museum of Art/Yale University Press, 2002, p. 51.

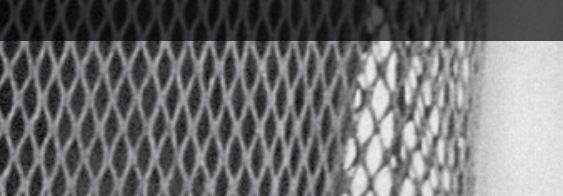

\section{Corpo e roupa na cultura}

As variações dinâmicas do olhar como metodologia

Muito se escreveu sobre o corpo e a roupa e suas relações na construção das culturas, mas, quando vamos analisar esse campo, temos a impressão de que ainda está tudo por ser estudado e que a tarefa de edificação nos desafia por inteiro. Áreas tão antigas quanto o próprio homem, o corpo e as vestes que o cobrem são abordados em várias intersecções do saber, o que exige dos investigadores um conjunto de olhares na sua trajetória de pesquisa.

Por definição, esse campo de estudos inter-relaciona essas duas áreas. Decorre de um "olhar especulativo" que entra em cena porque a curiosidade do sujeito, instigado pelas indagações propostas por essas áreas, leva-o além do conhecimento estabelecido. As possibilidades fazem com que o pesquisador intua percursos para a testagem das hipóteses explicativas; estas guiam o seu "olhar investigativo" para efetuar na totalidade recortes, enquadramentos, operando, como afirma Ferrara (1993), com sagacidade e tenacidade, e, segundo Landowski (2001), com comprometimento. Com esses fazeres e seus atributos, definimos as semiotizações do corpo e do que o veste como manifestações culturais em que as duas plásticas, a do corpo e a da roupa, definem-se imbricadas e conduzem o pesquisador a estabelecer nas suas buscas um entendimento dos mecanismos de funcionamento do sentido. 


\section{Um olhar para a própria pesquisa}

As articulações entre corpo, roupa e cultura têm sido foco de muitas pesquisas e é também o temário da nossa, com o propósito de fazer emergir maior compreensão do sujeito e de sua formação identitária na sociedade. Nossa investigação sobre essas articulações enfrenta sempre a mesma questão: de onde partir?

Continuamente o problema e as hipóteses determinam a abordagem. Com instigações várias, as problemáticas se multiplicam, apresentando-se ao olhar investigativo no seu vasto contexto. Podemos citar, entre outras: a efusão do setor da moda; o boom midiático do corpo; os simulacros que tanto o corpo quanto a moda criam dos corpos vestidos; o simulacro de quem cria a roupa, mas também o do corpo que veste a roupa $\mathrm{e}_{\mathrm{i}}$ ainda, o da sociedade pelos corpos vestidos; a produção dos poucos criadores que se tornam celebridades da moda ou, em número mais restrito, daqueles que são atemporais e vestem corpos de homens e mulheres para além de ciclos determinados, o que torna esses poucos criadores celebridades, e como eles inspiram tantos mais a aderir às suas concepções e proposições; como as realizações desses demiurgos fazem ser homens e mulheres; ou os modos de presença do corpo nos vários meios, com os crescentes cuidados que esses despertaram nos destinatários, como o culto da saúde e da beleza, para estes se adequarem aos padrões eleitos; como se dá a propagação pelos quatro cantos globais desses padrões e como eles se transformam em programas narrativos tendo como propósito a adesão dos destinatários; ou ainda de como as especificidades desses padrões configuram o gosto, o que é aceito como bom ou mau gosto, como moda, antimoda, fora da moda, antevisão da moda; ou, não de menor importância, quais são as consequiências da proliferação das faculdades de moda no país nas últimas duas décadas em razão do "bom negócio" desse ensino com uma grande procura de jovens que sonham em se tornar estilistas e atingir a fama.

Em torno dos tão poucos estilistas que fizeram história se tornando conhecidos por um estilo próprio no desenrolar do século XX, foi criada uma das mais férteis mitologias da modernidade. No âmbito geral, eles são produtores de linguagens, que articulam os sistemas do corpo e da roupa com seus elementos e regras de combinação em processos comunicacionais. Corpo e roupa expressam os afetos, sentimentos, conceitos e criam expressões aos pensamentos, posicionamentos nas modelações de suas plásticas. 0 estudo que propomos de sua construção visa então depreender o conjunto de seus elementos mínimos, os mecanismos de seus processamentos e as operações significantes de produção do sentido.

Na mitologia dos demiurgos, perguntamos como cada criador, cada marca, cada sujeito quando veste 0 seu corpo monta processos significantes nas suas produções, em que circulam os valores que nos permitem depreender o social que não está edificado, mas em contínua mutação, sendo a sua própria dinâmica o que 
o define. Os corpos vestidos são então construções do social, e analisá-los em suas manifestações é entender o processo de expressão de um eu, o do criador, o do destinador na sua grande gama de sujeitos possiveis - que tanto pode ser a marca, ou a cadeia midiática que a faz circular, ou o usuário, no seu estar vestido para estrelar nas suas cenas performativas,- 0 do destinatário, igualmente uma amplidão que configura a sociedade em que essa manifestação se dá como o seu próprio sujeito concretizado em pele (transformações do e no corpo) ou tecido (novas propostas para as roupas e moda). 0 campo da moda é tomado como campo aurático dos modernos demiurgos que buscam manter vivo o seu dom de fabulação, cuja base assentase em um culto à narratividade. As suas produções são seqüências de enunciados de estados e transformações que processam a visibilidade do ser, inclusive das suas camadas até então invisiveis que passam a ser vistas nas construções de linguagens. Movidos por esse poder de criadores de simulacro, criadores da aparência, é a própria magia de ser um transformador em potencial que move as ilusões, perigosas de fato, de que há várias entradas no campo de trabalho promissor no mundo da moda e que essas vias de acesso estão abertas. Os deuses são poucos e isso faz com que essa geração de graduandos se frustre em face das dificuldades. Bem poucos são os que conseguem o seu lugar no mundo dos heróis, das marcas, do sucesso pessoal e, conseguido isso, cabe analisar a parte das mídias na propagação dos novos deuses (ou seriam semideuses?). Quais papéis a mídia desempenha nessas construções? Como anunciando os fatos e feitos desses criadores, dos seus desfiles, das narrativas das top models nas, e fora das, passarelas, do público seleto de testemunhas oculares convidadas para os eventos fechados dos desfiles, como a mídia auto-sustenta o seu próprio lugar de fala? Os protagonistas, as testemunhas, como eles propagam a visão extraordinária dizendo ao grande público: "eu estive lá". "eu vi", "eu participo desse seleto mundo"?

Também no âmbito do corpo e de sua modelação, as faculdades de educação física, nutrição e medicina estética se entrecruzaram com os cursos de estética corporal, facial, visagismo, que, com dietas, alimentação saudável e balanceada, a partir de tantas fórmulas, combinadas a exercícios físicos, estão por aqui e acolá, delineando os tipos de gosto pela "boa e bela" forma, em detrimento da que rotulam "má e feia", que tipos de gosto são esses traçados por poucos eleitos para tantos aderentes? 0 universo global tem um campo importante de estudo nas circulações dos corpos vestidos, contrastando a sua órbita com a do universo local, com seus usos e costumes particulares, e entre esses opostos se estrutura 0 "glocal", que reúne nas produções tanto o global quanto o local. Que "glocal" é esse? Como são os processos de tradução e de transcriação que o definem?

Corpo, roupa, uso e moda têm sido ditado(s) pela(s) moda(s). A mobilidade desses ditames ressalta como os julgamentos estéticos são insubordinados a uma só axiomática. Gosto e falta de gosto; belo e feio; agradá- 
vel e desagradável; prazer e desprazer; estilo e falta de estilo são semanticamente múltiplos e caracterizadores do sujeito, do objeto que, assim, são posicionados em novas transições de sentido. Essa mobilidade e suas dinâmicas têm nos estimulado a debruçar sobre essas e outras questões com um olhar vago, especulativo, procurando apreender e explorar os modos de presença, as formas de gosto, de beleza, as formações dos estilos, das formas de aprazimento.

Passando do olhar vagante ao olhar constelar, ou do sinóptico ao multifocal, somos conduzidos à conformação de um olhar investigativo, ou semiotizador, que nos leva às explorações desses dois campos inter-relacionados com resultados que aumentam a compreensão e o entendimento da construção do sujeito no seio da vida social na contemporaneidade e em outras épocas.

Nossa abordagem nesta coluna é indicativa dos aspectos que temos desenvolvido na PUC-SP, no Programa de Estudos Pós-Graduados em Comunicação e Semiótica ao longo de mais de uma década, guiados pela teoria semiótica de Greimas e seus colaboradores dos quais destacamos as contribuições da sociossemiótica de Landowski e a semiótica plástica de Floch. ${ }^{1}$ Tendo como premissa que o corpo natural assim como as línguas (naturais) não se separam do mundo (natural), ao contrário, estão entrelaçados, nessas macrossemióticas, as categorias significantes são as mesmas constituintes das categorias do plano do conteúdo das linguagens. Esse operar entre expressão e conteúdo nos enreda nos desdobramentos complexos das figuras e de suas formas de dependência. As figuras do corpo e as da roupa, as figuras do corpo vestido são tratadas como figurativizações da cultura em um arranjo plástico da expressão que arrolam processamentos das aparências do sujeito, do social, ou seja, o estudo dos seus simulacros na acepção sociossemiótica do termo, enquanto modelo.

A expressão do corpo e da roupa se dá pelo movimento, o cinetismo, que é uma de suas características particulares que muito tem nos interessado nas várias interações entre os corpos em movimentação, em especial, do corpo com a roupa na constituição dos regimes de visibilidade que se imbricam com os regimes de subjetividade, de identidade. Vivemos em contextos em que nossa relação com o outro, quer seja este uma pessoa, um produto, uma coisa, quer seja uma vestimenta, recebe um tratamento de encontros entre corpos (objetais, mas também sujeitais). Além de que esses corpos significam justamente ao se pôr ou ser postos em relação a outro(s) corpo(s), marcando ações entre sujeitos em interação narrativa. Como temos postulado, tanto o corpo quanto a roupa podem ser considerados como um desses outros que têm um fazer que faz o sujeito ser, marcando a sua existência. A vestimenta com sua plástica, delineada em uma topologia com um volume, é um arranjo tridimensional de cores, formas, matérias que, no espaço e tempo que ocupam e determinam, realiza um percurso de constituição identitária ao dar visibilidade àquele que veste, o corpo vestido que significa o sujeito.

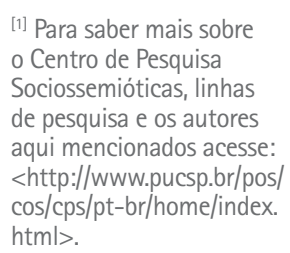

[1] Para saber mais sobre - Centro de Pesquisa Sociossemióticas, linhas de pesquisa e os autores aqui mencionados acesse: <http://www.pucsp.br/pos/ cos/cps/pt-br/home/index. html>.

\section{REFERÊNCIAS}

FERRARA, L. A. A ciência do olhar atento. In: Olhar Periférico. São Paulo: Edusp/FAPESP, 1993.

LANDOWSKI, E. 0 olhar comprometido. Galáxia São Paulo, Educ, n², p. 19-56, 2001 